\title{
Evaluation of bone turnover markers and serum minerals variations for predicting fracture healing versus non-union processes in adult sheep as a model for orthopedic research
}

\author{
Cristina P. Sousa ${ }^{\mathrm{a}, *}$, Mónica Lopez-Peña ${ }^{\mathrm{b}}$, Fernando M. Guzón ${ }^{\mathrm{b}}$, Humberto V. De Abreu ${ }^{\mathrm{c}}$, \\ Maurino R. Luís ${ }^{c}$, Carlos A. Viegas ${ }^{c, d}$, José Camassa ${ }^{c}$, Jorge T. De Azevedo ${ }^{\mathrm{e}, \mathrm{f}}$, \\ António S. Cabrita ${ }^{g}$, Rui L. Reis ${ }^{\mathrm{h}, \mathrm{i}}$, Manuela E. Gomes ${ }^{\mathrm{h}, \mathrm{i}}$, Isabel R. Dias ${ }^{\mathrm{c}, \mathrm{d}}$ \\ a Center Hospitalar of Porto, Largo Prof. Abel Salazar 4099-001 Porto, Portugal \\ ${ }^{\mathrm{b}}$ Department of Veterinary Clinics Sciences, Faculty of Veterinary Medicine, University of Santiago de Compostela, University Campus, Av. Carballo Calero, \\ 27002 Lugo, Spain \\ ${ }^{\mathrm{c}}$ Department of Veterinary Sciences, Agricultural and Veterinary Sciences School (ECAV), University of Trás-os-Montes and Alto Douro (UTAD), Quinta de \\ Prados, 5000-801 Vila Real, Portugal \\ d CITAB - Centre for the Research and Technology of Agro-Environmental and Biological Sciences, UTAD, Vila Real, Portugal \\ e Department of Animal Sciences, ECAV, UTAD, Vila Real, Portugal \\ ${ }^{\mathrm{f}}$ CECAV - Centre for Animal Sciences and Veterinary Studies, UTAD, Vila Real, Portugal \\ $\mathrm{g}$ Institute of Experimental Pathology, Faculty of Medicine, University of Coimbra, Rua larga, 3004-504 Coimbra, Portugal \\ h $3 B$ 's Research Group - Biomaterials, Biodegradables and Biomimetics, University of Minho, Headquarters of the European Institute of Excellence on Tissue \\ Engineering and Regenerative Medicine, AvePark, 4805-017 Barco, Guimarães, Portugal \\ i ICVS/3B's - PT Government Associate Laboratory, Braga/Guimarães, Portugal
}

A R T I C L E I N F O

Article history:

Accepted 15 May 2017

\section{Keywords:}

Bone turnover markers

Fracture healing process

Non-union

Delayed union

Critical size defect

Sheep

\section{A B S T R A C T}

Bone turnover markers (BTMs) have been considered as an auxiliary method of following the fracture healing process and for early prediction of impaired bone healing. A better understanding of the potential of BTMs in this application could allow for earlier interventions and improved patient care. The aim of this study with a large animal experimental model was to assess the variation of bone formation markers - namely the total alkaline phosphatase (ALP) and its bone-specific isoform (BALP), serum concentration of intact osteocalcin (OC), N-terminal propeptide type III procollagen (PIIINP) and of bone resorption markers - namely tartrate resistant acid phosphatase (TRAP) and deoxypyridinoline crosslink (DPD) during the first stages of a normal fracture healing process and of a segmental critical size defect (CSD), which progresses to a non-union process. Thirty healthy female sheep (Portuguese Churra-da-TerraQuente breed), approximately 4-years-old, were enrolled in this study. Jugular venous blood samples were collected pre-operatively and at 1, 2, 3, 4, 6, 8, 10 and 12 post-operative weeks. The animals of the CSD group showed significant lower serum levels of BALP, OC and significant higher serum PIIINP levels at early stages of the fracture healing process, compared with animals that progressed in a normal fracture healing process. Serum BALP, OC and PIIINP levels could be useful as non-invasive auxiliary tools with other complementary methods for predicting the outcome of traumatic bone fractures.

(c) 2017 Elsevier Ltd. All rights reserved.

\section{Introduction}

Bone turnover markers (BTMs) reflect the bone turnover process and they have been largely applied in association with dual energy [1] X-ray absorptiometry to study the pathogenesis of post-menopausal osteoporosis, to assess the response to anti-

\footnotetext{
* Corresponding author.

E-mail address: cristinamariapsousa@gmail.com (C.P. Sousa).
}

resorptive treatment and to predict fracture risk in osteoporotic patients $[1,2]$.

The BTMs have also been applied in the study of fracture healing, supplying information about the organic response at the fracture site and to the selected fixation methods [3,4]. Some studies have assessed the prognostic value of BTMs for the early detection of an impaired fracture healing process and have verified a different pattern of BTMs variation in patients with a normal fracture healing process versus delayed healing or even atrophic 
non-union development [5-7]. Nevertheless, the clinical studies present some difficulties and limitations concerning the selection of patients that should comprise the different clinical groups, since a great number of factors can interfere in the progression of the fracture healing process and its classification. Some of the variability factors are associated with patient health conditions (age, presence of comorbidities that interfere in bone metabolism, tobacco consumption, etc) and to various bone fracture conditions which may be presented (etiology, fracture classification, severity of the surrounding soft tissue involvement and the time that it takes to heal) [8]. Therefore, a better understanding of the full potential of BTMs in controlled experimental conditions will confirm its suitability as a potential indicators of fracture healing disturbances, namely for delayed union or non-union processes, with a view to earlier interventions to assist and/or accelerate fracture healing. To date, no studies performed in pre-clinical large animal models have been done which allow obtaining controlled patterns of variation of BTMs during the expected evolution of a normal fracture healing process versus in an experimentally induced atrophic non-union event.

To that end, the aim of this study was to assess the variation of bone formation markers - namely total alkaline phosphatase (ALP) and its bone-specific isoform (BALP), serum concentration of intact osteocalcin (OC), N-terminal propeptide procollagen type III (PIINP) and bone resorption markers, namely tartrate resistant acid phosphatase (TRAP) and deoxypyridinoline crosslink (DPD), and to evaluate their correlation with serum minerals during the first stages of an osteotomy healing process versus a segmental bone critical size defect (CSD), which definitively progresses to a non-union process, in a large animal experimental model. The main purpose was to verify whether the pattern of variation of these biomarkers could be correlated with specific stages of the bone fracture healing process, in conformity with local cell characteristics and newly formed tissues during successive stages of bone callus formation, in both a normal fracture healing process and during the evolution to an atrophic non-union process.

\section{Materials and methods}

\section{Animals and surgical protocols}

The animal maintenance and all experiments were reviewed and approved by the National Animal Use and Care Committee and undertaken according to the regulations of the European Community Legislation on Animal Care (Authorization DGV Of. $\mathrm{n}^{\circ}$ 0420/000/000/2009).

Thirty healthy female sheep (Portuguese Churra-da-TerraQuente breed) approximately 4-years-old and with an average weight of $45 \mathrm{~kg}$ were acclimatised for 6 weeks before the collection of blood samples and surgical protocol procedure. The animals were permanently housed indoors in loose groups of 6 sheep and kept under a constant photoperiod cycle (light: 7:00 a.m. to 7:00 p. m.; dark: 7:00 p.m. to 7:00 a.m.), controlled temperature $\left(20 \pm 2{ }^{\circ} \mathrm{C}\right)$ and humidity $(50 \pm 10 \%)$. This husbandry protocol was used in order to minimize the influence of seasonal variation [9] and circadian rhythm on bone remodelling and serum levels of BTMs, especially ovine OC $[10,11]$, since an increase in the rate of bone formation during the evening and night has previously been reported [11,12]. The animals were fed with hay supplemented with $0.250 \mathrm{~kg} /$ day of concentrate per animal, and water provided ad libitum. The diet offered was estimated at $1.20 \times$ energy maintenance requirements according to the National Research Council recommendations [13]. The composition of the feeds is shown in Table 1 . The animals selected for this study were subjected to a previous evaluation of their state of health by clinical examination, complete blood count and general blood biochemical
Table 1

Dry matter (DM) and chemical composition of feeds.

\begin{tabular}{lll}
\hline & \multicolumn{2}{l}{ Food } \\
\cline { 2 - 3 } & Grass hay & Concentrate \\
\hline DM $(\mathrm{g} / \mathrm{kg})$ & 88.5 & 90.4 \\
Chemical composition* & $(\mathrm{g} / \mathrm{kg}$ DM) & \\
Ash & 5.9 & 8.5 \\
NDF & 73.3 & 31.6 \\
CP & 6.1 & 20.7 \\
\hline
\end{tabular}

${ }^{*} \mathrm{CP}$ - crude protein; NDF - neutral detergent fiber.

analysis. The animals were examined daily and their welfare monitored during the entire period of this study.

Six animals were used as an untreated control group for the BTMs study. Twenty-four animals were divided in two experimental groups and an osteotomy or a segmental bone CSD process was induced. These animals were pre-medicated with acepromazine maleate (5 mg EV, Calmivet; Univete, Lisboa, Portugal) and butorphanol tartrate $(0.06 \mathrm{mg} / \mathrm{kg}$ EV, Torbugesic; Fort Dodge Veterinaria, S.A., Vall de Vianya, Girona, Spain) and anaesthesia was induced with propofol $2 \%(20 \mathrm{mg} / \mathrm{ml}$, Propofol-Lipuro; B. Braun, Melsungen, Germany) and maintained, after tracheal intubation, by inhalation of a mixture of $1.5 \%$ isoflurane (IsoFlo; Esteve Farma, Carnaxide, Portugal) and oxygen. After sterile skin preparation and draping of the left hindlimb, an $18-\mathrm{cm}$ longitudinal skin incision was made in its internal face to access the medial diaphysis of the tibia. In one experimental group, a mid-diaphysis tibial osteotomy was performed $(n=12)$, stabilised with an 8-hole 4.5-mm Broad Dynamic Compression Plate (Ref. 226.080; Synthes, Davos, Switzerland), contoured to the medial aspect of the diaphysis and applied in a neutralization function. In the other group, an 8-hole 4.5-mm Broad Lengthening Plate (Ref. 227.810; Synthes, Davos, Switzerland) was contoured to the medial aspect of the diaphysis and provisionally attached to the tibia shaft using two $4.5-\mathrm{mm}$ unicortical screws. The remaining holes were drilled in both cortices, also measured and tapped for 4.5-mm screws. The plate was removed and a 3-cm segmental bone defect created $(n=12)$, by performing two parallel osteotomies. In these animals, the periosteum was carefully removed in the bone defect area. The tibia was then restored to its original length using longitudinal traction and stabilized by reapplying the plate, using the pre-drilled holes where the 4.5$\mathrm{mm}$ screws had been inserted. In both groups, the wound was closed in three layers - the fascial, subcutaneous and skin layers. Analgesia was accomplished by the administration of flunixin meglumine $(1 \mathrm{mg} / \mathrm{kg}, \mathrm{IM}, \mathrm{q} 24 \mathrm{~h}$, Finadyne; Vetlima, Lisboa, Portugal) for $72 \mathrm{~h}$, and the animals were subjected to antibiotherapy with amoxicillin $(15 \mathrm{mg} / \mathrm{kg}$, IM, q48 h, Clamoxyl LA; Laboratórios Pfizer, Lda., Barreiro, Portugal) during the first week. Wound dressings were applied around the incision, during the first post-operative two weeks, and frequently changed. The animals were kept in pens during the first two post-operative weeks, for easier handling in the immediate post-operative period and for restriction of movements, after which unrestricted ambulation was allowed. In each group, the operated animals were randomly assigned into three subgroups which were euthanized at $3(n=3), 6(n=3)$ and 12 weeks $(n=6)$ postoperatively, with an IV injection of pentobarbital sodium (Eutasil; Sanofi Veterinária, Miraflores, Algés, Portugal) after sedation with detomidine (Dormosedan; Pfizer, Auckland, New Zealand).

\section{Collection of blood samples}

In the osteotomy and segmental bone CSD groups, jugular venous blood samples were collected pre-operatively prior to 
sedation for surgery, and at 1, 2, 3, 4, 6, 8, 10 and 12 weeks postoperatively. In the control group, the blood samples were collected at equal intervals. Each of the samples was harvested into serum tubes without anticoagulant (SARSTEDT - Monovette - Serum Gel S; Nümbrecht, Germany), between 9:00 and 10:00 a.m. and before feeding in order to reduce the influence of circadian rhythm in serum levels of BTMs. Within 30 min of collection, the blood was centrifuged at $3000 \mathrm{rpm}$ for $10 \mathrm{~min}$ and the resulting serum was harvested rapidly into $2 \mathrm{ml}$ Eppendorf tubes and stored at $-20^{\circ} \mathrm{C}$ for serum mineral analyses and at $-80^{\circ} \mathrm{C}$ for BTM analyses.

\section{Serum biochemical analysis}

The serum BALP activity was determined with an immunocapture method in a microtiter strip format using a monoclonal anti-BALP antibody adsorbed onto strips that captured the BALP in the sample. The enzyme activity of the captured BALP activity was determined with para-nitrophenylphosphate ( $p$ NPP) substrate (METRA BALP EIA kit; QUIDEL Corporation, San Diego, CA, USA). The serum levels of intact OC were determined by a competitive method that uses OC coated onto strips, a mouse anti-OC antibody, an anti-mouse IgG-ALP conjugate and a p-NPP substrate (METRA Osteocalcin; QUIDEL Corporation, Santa Clara, CA, USA). The DPD serum levels were assessed with a competitive enzymatic immunoassay in a microassay stripwell format. DPD in serum competes with ALP conjugated DPD for binding to monoclonal anti-DPD antibody coated on the strip. The reaction is detected with p-NPP substrate (MicroVue tDPD; QUIDEL Corporation, Santa Clara, CA, USA). The assays were performed in duplicate, according to the manufacturer's instructions, and read in a microplate reader (Multiskan EX; MTX Lab Systems, Inc., Vienna, VA, USA), especially adapted for enzyme-linked immunosorbent assay (ELISA). The Metra immunoassays have cross-reactivity with ovine species. The METRA BALP EIA test has been used in several studies in sheep $[11,14]$ and the cross-reactivity between the ovine and human OC is reported as $83 \%$ [15].

The amount of PIIINP in serum was measured using an available human radioimmunoassay kit (PIIINP Orion Diagnostica; Espoo, Finland), with cross-reactivity with sheep [16] and read in a gamma counter (Berthold C-12, Berthold Technologies GmbH \& Co. KG, Bad Wildbad, Germany).

Commercially available kits from Beckman Coulter (Carnaxide, Portugal), were used for the measurement of total ALP serum activity (ALP, Ref. 60 04) and for serum minerals concentrations, namely calcium (Ca) (Ca-Arsenazo, Ref. 60 117), phosphorus (P) (Inorganic Phosphorus, Ref. 6122 ) and magnesium (Mg) (Magnesium, Ref. 61 89) using a colorimetric method, by means of molecular absorbance spectrophotometry, and read with an automated biochemistry analyser (Olympus AU400; Olympus America Inc., PA, USA). TRAP serum activity (ACP, Ref. 17304; Sentinel Diagnostics, Milano, Italy) was also measured by means of molecular absorbance spectrophotometry ${ }^{16}$ and read in the same chemistry analyser. All the assays were performed in duplicate, and according to the manufacturer's instructions.

\section{Radiographic exams}

The courses of the osteotomy healing and the non-union process were monitored by radiographic exams. Conventional Xray films (Bucky Diagnost; Philips Medical Systems, USA) were taken just after surgery, and subsequently each month, under sedation, in an anterior-posterior projection ( $70 \mathrm{kV}, 2.5 \mathrm{mAs})$, with a focus distance of $1-\mathrm{m}$. All radiographs were assessed for features of bone healing such as sclerosis at fracture margins, periosteal reaction, callus mineralisation and bridging of the fracture gap.

\section{Histological analysis}

Sheep tibiae specimens were fixed in neutral-buffered formalin. Specimens were cut longitudinally and a mid-section of each tibia specimen was decalcified for 24-36 $\mathrm{h}$ (depending on the thickness) by immersion in a commercial solution containing EDTA disodium salt (volume ratio specimen/decalcifier 1:100) (Osteodec; Bio-Optica, Milano, Italy) with an acid buffer. After reconditioning, using three steps of PBS at pH 7.4, the specimens were embedded in paraffin. Sections of $5 \mathrm{~mm}$ thickness were stained with Haematoxylin and Eosin (H\&E) and Masson Trichrome staining for evaluation by light microscopic examination. Masson Trichrome staining allows visualizing the soft callus (fibrous tissue plus cartilage) and the hard callus tissue (newly formed bone).The specimens were placed on a motor-driven positioning systems (Märzhäuser Wetzlar GmbH \& Co KG; Wetzlar-Steindorf, Germany) and photographed using a digital camera (1 pixel equal to $1.63 \mathrm{~mm}$ $(\times 4)$, DP71; Olympus, Tokyo, Japan) adapted for a microscope (BX51; Olympus, Tokyo, Japan). The new bone of the fracture callus and the surrounding soft tissues were the region of interest (Photoshop CS3; Adobe Photoshop ${ }^{\circledR}$, Adobe, San Jose, CA, USA). Image analysis was conducted based on rule-sets considering the colour of the new bone formation (Image ProPlus; Bethesda, CA, USA) following control by light microscopy. "Bone area per tissue area" (BA/TA) was determined to a square of $3 \mathrm{~cm}$ centred in the defect (in the bone osteotomy). BA/TA was calculated by dividing the area of bone area (BA) by the total tissue surface (TA) present in the region of interest.

\section{Statistical analysis}

To determine statistical differences between experimental groups, and between experimental groups and the control group a Mann-Whitney $U$ test was performed. The baseline values obtained in each group were compared with a Wilcoxon test using the values observed during the 12 weeks of observation. The degree of correlation between the different biochemical parameters was assessed using a Spearman correlation test. All statistical analyses were performed with SPSS (SPSS 20, SPSS Inc, Chicago, IL, USA) statistical software. The $P$-values and $R$-values of correlations were considered significant at $P<0.05$.

\section{Results}

The animals included in this work showed progressive recovery, free of complications. The radiographic examination showed the osteotomy group presenting a suitable and progressive fracture healing process which was very consistent between animals, although this process wasn't fully complete at the 12th postoperative week. In the CSD group an atrophic non-union process was achieved in all the animals. However, some mineralized tissue that proliferated from the ends of the proximal and distal bone fragments was also observed in the fracture gap (Fig. 1).

The histologic evaluation of the bone sections of the osteotomy group demonstrated new bone formation and the appropriate reestablishment of the cortex contralateral to the plate. Additionally, a lower cortical bone tissue formation on the sites beneath the plate was observed, which could be related to impairment of the vascularization due to the placement of the plate or by decreased stimuli to bone formation caused by the reduction of load weight bearing [17]. The plate allowed the distribution of some load over the contralateral cortex, however directly under the bone plate the bone tissue was subject to a lower load due to the rigidity of the plate, thus justifying the different stimulation of bone tissue development. In the histologic sections of the atrophic non-union process, some indication of bone healing by the neoformation of 

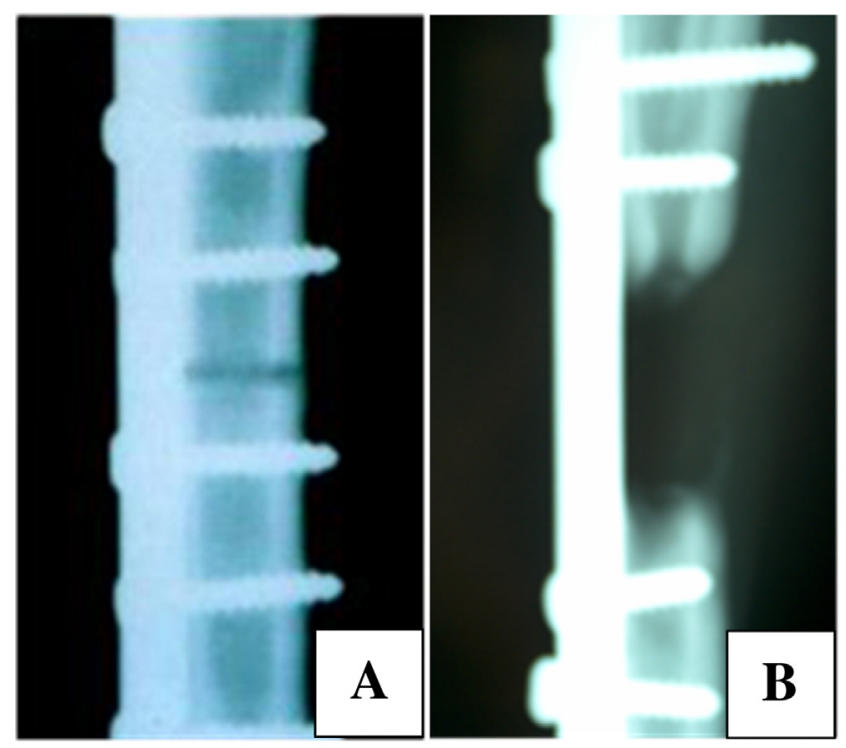

Fig. 1. Radiographs of the (A) osteotomy group and (B) CSD group at 12th postoperative week.

trabecular bone appearing on the ends of the experimental bone fracture fragments was found; however, the defects were merely filled with fibrous and muscle tissue which collapsed from the surrounding soft tissues.

The histomorphometric analysis demonstrated that the fracture healing process in the CSD group did not present significant differences between the distinct time-points. Otherwise, in the osteotomy group, the mineralized callus increased during the course of this study, with significant differences between the three different time points $(P<0.05)$. Significant differences were observed between osteotomy and CSD group at the 12th week. However, it should be mentioned that the new bone formation presented an obvious variability between animals of the same experimental group (Table 2).

Excluding DPD, all BTMs revealed broad inter-individual variations, during the entire 12 -week period of observation. In the control group, significant time-dependent changes were seen concerning BALP serum activity during the observed 12-week period $(P<0.05)$. In this group, for the others parameters, timedependent changes were not verified during the study period.

In the osteotomy group, the ALP and BALP serum activities and OC serum levels observed during the fracture healing process were significantly higher compared to their relevant preoperative normal values $(P<0.01, P<0.05, P<0.001$, respectively). The ALP serum activity was higher in the control group than in the osteotomy and CSD group. The osteotomy group also showed an increase in their ALP serum activity from the $3^{\text {rd }}$ postoperative week (Fig. 2). No significant differences could be observed for the serological course of ALP between the osteotomy and CSD group.

Table 2

Histomorphometrical analysis.

\begin{tabular}{|c|c|c|c|c|c|c|c|}
\hline \multirow[b]{2}{*}{$\begin{array}{l}\mathrm{BA} / \mathrm{TA} \\
(\%)\end{array}$} & & \multicolumn{3}{|c|}{ Osteotomy } & \multicolumn{3}{|l|}{ CSD } \\
\hline & & 3 week & 6 week & 12 week & 3 week & 6 week & 12 week \\
\hline & Median & 2.60 & 38.00 & $41.79^{\dagger \dagger}$ & 1.84 & 2.10 & 8.40 \\
\hline & Minimum & 1.30 & 5.60 & 11.85 & 0.80 & 1.60 & 2.50 \\
\hline & Maximum & 4.2 & 57.00 & 70.03 & 2.60 & 9.90 & 18.34 \\
\hline & $\mathrm{CV}$ & 64.8 & 77.5 & 53.7 & 76.5 & 78.0 & 70.0 \\
\hline
\end{tabular}

${ }^{\dagger}$ Significant compared with CSD group for the same post-operative time $(p<0.01)$. BA: bone area: TA: tissue area.
The animals of the osteotomy group showed an increase of their BALP serum activity until the $3^{\text {rd }}$ postoperative week. The BALP serum activity subsequently returned to the preoperative level around the $8^{\text {th }}$ postoperative week. The animals of the CSD group also showed an increase of their BALP serum activity until the 4th postoperative week followed by a decrease around the $6^{\text {th }}$ postoperative week (Fig. 2). It was also observed that the animals of the osteotomy group showed higher values of their BALP serum activity than the animals of the CSD group, during the entire postoperative period, with significant values until the $6^{\text {th }}$ week.

The osteotomy group showed increased OC levels until the $2^{\text {nd }}$ week, declining in the $3^{\text {rd }}$ week, followed by an increase around the $4^{\text {th }}$ postoperative week, with the values being higher than the preoperative levels during the entire study period. In the CSD group, the course of $\mathrm{OC}$ showed a significant increase just around the 8th week (Fig. 2). The osteotomy group showed also higher values than the animals of CSD group, during the postoperative period, with significant levels until the $4^{\text {th }}$ week.

The osteotomy group showed a slight increase in their TRAP serum activity between the $4^{\text {th }}$ and the $6^{\text {th }}$ postoperative weeks. However, no significant differences were observed in the remaining postoperative time-points compared with those obtained preoperatively. A similar pattern of variation was observed in the CSD group (Fig. 2). Significant differences were observed between groups at the $3^{\text {th }}$ postoperative week.

The animals in the osteotomy group did not present differences for the serological course of PIIINP levels during the postoperative period. Otherwise, PIIINP serum levels observed during the postoperative period in the CSD group were significantly higher than their preoperative normal values $(P<0.001)$. This group showed significant time-dependent changes of PIIINP serum levels during the entire postoperative period (Fig. 2). It was also observed that the serum levels of PIIINP were significantly higher in the CSD group than in the osteotomy group throughout the postoperative period.

In the osteotomy group, an increase of DPD serum levels was observed around the $4^{\text {th }}$ postoperative week while in the CSD group a significant decrease from the preoperative values was observed around the $6^{\text {th }}$ postoperative week (Fig. 2). Significant differences between groups were observed at the $4^{\text {th }}$ postoperative week.

The serological course of serum minerals in the studied groups was not affected by the fracture healing process, and significant differences were not observed during the postoperative period or between the different groups (Fig. 2).

The degree of correlations between the biochemical parameters in study was significant between ALP and Ca $(R=0.37, P<0.05)$, ALP and $\mathrm{P}(R=-0.41, P<0.05)$, ALP and OC $(R=0.44, P<0.05)$, BALP and OC $(R=0.28, P<0.05)$, BALP and DPD $(R=0.27, P<0.05)$, OC and DPD $(R=0.39, P<0.05), \mathrm{OC}$ and $\mathrm{Ca}(R=0.54, P<0.01)$ and $\mathrm{Ca}$ and $\mathrm{P}(R=-0.352, P<0.05)$, in the osteotomy group (Table 3$)$. In the CSD group significant correlation was observed between ALP and Ca $(R=0.38, P<0.05)$, ALP and $\mathrm{P}(R=0.33, P<0.05)$, ALP and DPD $(R=-0.397, P<0.05)$, BALP and OC $(R=0.25, P<0.05)$, BALP and PIIINP $(R=0.24, P<0.05)$, OC and PIIINP $(R=0.21, P<0.05)$, PIIINP and TRAP $(R=0.29, P<0.05)$ and $C a$ and $\mathrm{P}(R=-0.401, P<0.05)$ (Table 4).

\section{Discussion}

The aim of this study was to evaluate whether BTMs are a suitable prognostic markers to assess the fracture healing process. A large animal model was used for this purpose. In order to exclude the influence of variability sources that have a clear influence on serum levels of BTMs an osteotomy or a CSD was induced in sheep 
G Model

JINJ 7251 No. of Pages 8

ARTICLE IN PRESS

C.P. Sousa et al./Injury, Int. J. Care Injured $x x x$ (2017) $x x x-x x x$

5
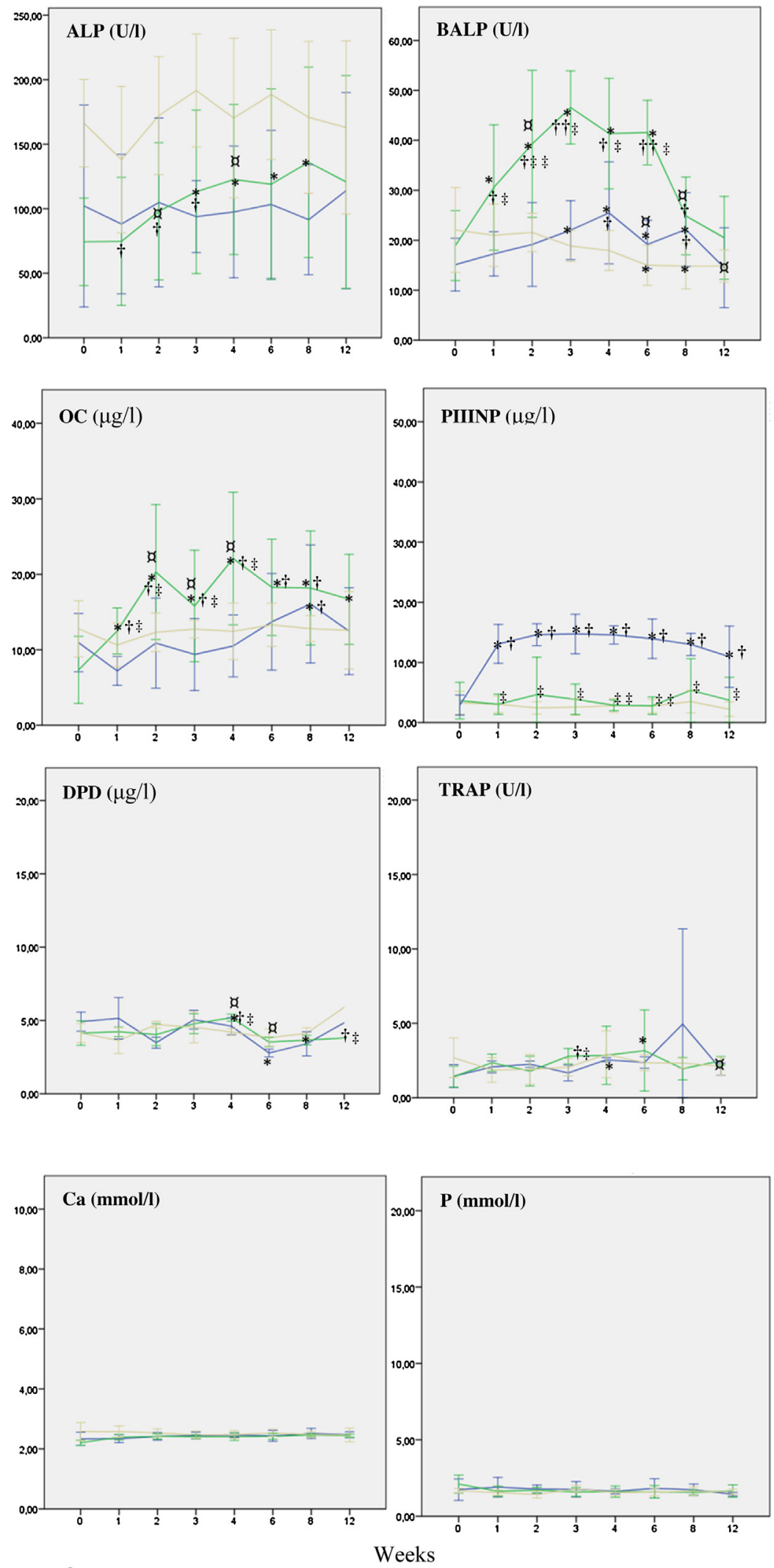

Osteotomy group

Weeks

CSD group

Control group

Fig. 2. Serological course of bone turnover markers and serum minerals during the postoperative period (Mean \pm S.D. green line: osteotomy group; blue line: CSD group; brown line: control group; * significant differences compared to their preoperative (baseline) values; significant differences compared to previous time-point; ${ }^{\dagger}$ Significant compared with control group for the same postoperative time $\left({ }^{\dagger} p<0.05,{ }^{\dagger \dagger} p<0.01\right)$; ${ }^{\ddagger}$ Significant compared with CSD for the same postoperative time $\left({ }^{\ddagger} p<0.05,{ }^{\ddagger \ddagger} p<0.01\right)$ ).

Please cite this article in press as: C.P. Sousa, et al., Evaluation of bone turnover markers and serum minerals variations for predicting fracture healing versus non-union processes in adult sheep as a model for orthopedic research, Injury (2017), http://dx.doi.org/10.1016/j. injury.2017.05.025 
Table 3

Correlations between BTM and serum minerals in the osteotomy group.

\begin{tabular}{|c|c|c|c|c|c|c|c|c|}
\hline & $\operatorname{ALP}(U / 1)$ & $\operatorname{BALP}(\mathrm{U} / \mathrm{l})$ & $\mathrm{OC}(\mu \mathrm{g} / \mathrm{l})$ & PIIINP $(\mu \mathrm{g} / \mathrm{l})$ & $\mathrm{DPD}(\mu \mathrm{g} / \mathrm{l})$ & TRAP $(\mathrm{U} / \mathrm{l})$ & $\mathrm{Ca}(\mathrm{mmol} / \mathrm{l})$ & $\mathrm{P}(\mathrm{mmol} / \mathrm{l})$ \\
\hline $\operatorname{ALP}(\mathrm{U} / \mathrm{l})$ & $R=1.00$ & & & & & & & \\
\hline BALP $(\mathrm{U} / \mathrm{l})$ & $R=0.20$ & $R=1.00$ & & & & & & \\
\hline $\mathrm{OC}(\mu \mathrm{g} / \mathrm{l})$ & $\begin{array}{l}{ }^{*} R=0.44 \\
P=0.02\end{array}$ & $\begin{array}{c}{ }^{*} R=0.28 \\
P=0.006\end{array}$ & $R=1.00$ & & & & & \\
\hline PIIINP $(\mu g / l)$ & $R=-0.03$ & $R=-0.0239$ & $R=0.05$ & $R=1.00$ & & & & \\
\hline $\mathrm{DPD}(\mu \mathrm{g} / \mathrm{l})$ & $R=0.016$ & $\begin{array}{l}{ }^{*} R=0.27 \\
P=0.006\end{array}$ & $\begin{array}{l}{ }^{*} R=0.39 \\
P=0.0001\end{array}$ & $R=-0.06$ & $R=1.00$ & & & \\
\hline TRAP (U/I) & $R=-0.030$ & $R=0.161$ & $R=0.10$ & $R=-0.14$ & $R=-0.07$ & $R=1.00$ & & \\
\hline $\mathrm{Ca}(\mathrm{mmol} / \mathrm{l})$ & $\begin{array}{l}{ }^{*} R=0.37 \\
P=0.001\end{array}$ & $R=0.14$ & $\begin{array}{l}{ }^{*} R=0.54 \\
P=0.001\end{array}$ & $R=-0.16$ & $R=-0.04$ & $R=0.14$ & $R=1.00$ & \\
\hline $\mathrm{P}(\mathrm{mmol} / \mathrm{l})$ & $\begin{array}{l}{ }^{*} R=-0.41 \\
P=0.004\end{array}$ & $R=-0.14$ & $R=-0,21$ & $R=0.034$ & $R=0.10$ & $R=0.37$ & $\begin{array}{l}{ }^{*} R=-0.35 \\
P=0.004\end{array}$ & $R=1.00$ \\
\hline
\end{tabular}

"Significant values

tibia, under standardized conditions, which progressed in a normal healing process or an atrophic non-union process, respectively.

It has been estimated that $5-10 \%$ of all patients with long bone fractures will develop impaired fracture healing processes, namely delayed union and non-union processes [17]. Therefore, there is a real need for clinicians to have tools to better assess the fracture healing process, which can improve patients care. Several studies have demonstrated that serum and urinary BTMs are capable of reflecting fracture healing, with their levels dependent on the location, type and size of the fracture [3,4]. Although different serum BTMs levels are associated with different stages of the healing process, their clinical effectiveness for early prediction of impaired fracture healing processes is not clear, with different clinical trials presenting heterogeneous results [18].

This study demonstrated similar and simultaneous variations for BALP and OC serum values throughout the entire post-operative period in both experimental groups under study. When compared with the untreated control group it was evident that these parameters are influenced by the fracture healing process. BALP is a membrane bound enzyme which is synthesized and expressed at relatively high levels by osteoblasts during the production of osteoid and several studies indicate its involvement in the mineralization of the bone extracellular matrix (ECM)[19,20]. The $\mathrm{OC}$ is a non-collagenous bone protein, also synthesized by osteoblasts and present in the ECM, representing 15-20\% of the non-collagenous bone ECM [21]. Therefore, in the present study, the increase in the osteotomy group of BALP serum activity and OC serum levels during the post-operative period may be associated with an active synthesis and maturation stage of bone ECM by osteoblasts. The high significance of the correlation verified between serum BALP and OC, OC and $\mathrm{Ca}$ and between $\mathrm{OC}$ and $\mathrm{P}$ supports a probable association between these parameters, the involvement of BALP and OC in the synthesis and the mineralization process of the osteoid. The lower serum OC and BALP levels in the CSD group could reflect a reduction in bone formation associated with poor osteoblastic activity. Nevertheless, significant differences concerning new bone formation were not observed, at the 3rd and 6th post-operative weeks, when the histomorphometrical results were assessed, which could be related with the small number of animals incorporated in this analysis and with the significant variability that was observed (Table 2).

Concerning BALP activity, Emami et al. [22] also found lower levels in patients with delayed union at an early time-point during the fracture healing process, namely at the 4 th post-traumatic week, than in patients with a normal bone union process. However, these results are not in accord with results obtained by Herrman et al. [23], Marcelli et al. [6] and Moghaddam et al. [5], where serum BALP activity was not capable of predicting bone fracture healing outcome, because significant differences were not observed in serum BALP activity during the healing process, despite different outcomes. In studies by Oni et al. [24] and Herrmann et al. [23] in patients with diaphyseal fractures of long bone stabilized with conservative and osteosynthesis techniques, the sequential measurement of serum OC concentration was a valid aid in the early detection of patients at risk of developing an impaired union process. However, Oni et al. [24] reported lower OC concentration throughout the entire study period in the group of patients that progressed to impaired bone union than the group with a normal bone union. In turn, Herrmann et al. [23] observed a delay in the rise of the OC concentration in the group of patients that presented an impaired healing process.

The serum levels of ALP are the sum of four isoenzymes: intestinal, placental, liver and bone. The BALP and the liver isoforms represent the most relevant fraction of the total ALP

Table 4

Correlations between BTM and serum minerals in the CSD group.

\begin{tabular}{|c|c|c|c|c|c|c|c|c|}
\hline & $\operatorname{ALP}(\mathrm{U} / \mathrm{l})$ & $\operatorname{BALP}(\mathrm{U} / \mathrm{l})$ & $\mathrm{OC}(\mu \mathrm{g} / \mathrm{l})$ & PIIINP $(\mu \mathrm{g} / \mathrm{l})$ & DPD $(\mu g / l)$ & TRAP $(\mathrm{U} / \mathrm{l})$ & $\mathrm{Ca}(\mathrm{mmol} / \mathrm{l})$ & $\mathrm{P}(\mathrm{mmol} / \mathrm{l})$ \\
\hline $\operatorname{ALP}(\mathrm{U} / \mathrm{l})$ & $R=1.00$ & & & & & & & \\
\hline BALP (U/I) & $R=0.15$ & $R=1.00$ & & & & & & \\
\hline $\mathrm{OC}(\mu \mathrm{g} / \mathrm{l})$ & $R=0.05$ & $\begin{array}{l}{ }^{*} R=0.25 \\
P=0.02\end{array}$ & $R=1.00$ & & & & & \\
\hline PIIINP $(\mu \mathrm{g} / \mathrm{l})$ & $R=-0.11$ & $\begin{array}{l}{ }^{*} R=0.23 \\
P=0.019\end{array}$ & $\begin{array}{c}{ }^{*} R=0.2 \\
P=0.04\end{array}$ & $R=1.00$ & & & & \\
\hline DPD $(\mu \mathrm{g} / \mathrm{l})$ & $\begin{array}{l}{ }^{*} R=-0.40 \\
P=0.005\end{array}$ & $R=0.01$ & $R=-0.15$ & $R=0.12$ & $R=1.000$ & & & \\
\hline TRAP (U/l) & $R=0.04$ & $R=0.18$ & $R=0.28$ & $\begin{array}{c}{ }^{*} R=0.29 \\
P=0.04\end{array}$ & $\begin{array}{l}{ }^{*} R=-0.31 \\
P=0.03\end{array}$ & $R=1.00$ & & \\
\hline $\mathrm{Ca}(\mathrm{mmol} / \mathrm{l})$ & $\begin{array}{c}{ }^{*} R=0.38 \\
P=0.008\end{array}$ & $R=-0.005$ & $R=0.08$ & $R=-0.15$ & $R=0.08$ & $R=0.22$ & $R=1.00$ & \\
\hline $\mathrm{P}(\mathrm{mmol} / \mathrm{l})$ & $\begin{array}{l}{ }^{*} R=-0.33 \\
P=0.02\end{array}$ & $R=0.20$ & $R=0,096$ & $R=0.16$ & $R=0.42$ & $R=0.09$ & $\begin{array}{l}{ }^{*} R=-0.40 \\
P=0.005\end{array}$ & $\begin{array}{l}R= \\
1.000\end{array}$ \\
\hline
\end{tabular}

"Significant values. 
activity, with an almost equal contribution to about 95\% of this enzyme [19]. In the present study, were found differences in the serum levels of ALP between control, osteotomy and CSD groups, with the control group having higher values than the other two experimental groups. However, considering the variation pattern observed for BALP, it would be expected that the osteotomy group animals would present higher values. Despite the controlled environment of the experiment, the presence of variables, which were not considered and which could influence the remaining isoforms cannot be excluded.

In contrast to a previous experimental study conducted in sheep by Klein et al. [25] and in accordance with a clinical trial conducted by Kurdy et al. [26], the serum PIIINP levels appear to be suitable for the early detection of an impaired healing process. Kurdy et al. found significantly higher PIIINP values at the 10th postoperative week in patients with delayed union than in patients who presented a suitable fracture healing process [26]. In this work the higher PIIINP levels observed in the CSD group are supported by histological findings from another study which observed high amounts of collagen type III expressed by mature osteoblasts on woven bone surfaces in abnormal healing fractures and, in contrast, normal fracture healing processes presented collagen type III expression only at early stages, and it is very rarely seen in osteoblasts [27]. Klein et al. [25] performed a standardized osteotomy on the tibia, which was stabilized with either an external fixator or with a nail locked with medio-lateral inserted bolts. During the healing process, interfragmentary movements and axial torsion was significantly higher in the group stabilized with the tibial nail than in the group with external fixators. Therefore, since the degree of stability at the bone ends was different, it should be expected that the groups presented distinct healing evolutions, with the first group showing a delayed union compared to the second group. Despite differences on the level of fracture callus consolidation, the serum PIIINP were not sensitive enough to detect changes in the healing process and no significant differences were observed [25]. In regard to the limitations of experimental studies, and in comparison to clinical situations, this model could not completely demonstrate the pathophysiological mechanisms underlying an impaired healing process.

The results of the present work are able to support the previously described findings of lower levels of bone resorption markers at an early time-point in the impaired healing group compared with the normal healing group [5]. In other studies, serum TRAP levels have proved to be a promising marker of bone resorption, being sensitive, specific and capable of detecting early bone metastases from breast cancer [28], predicting the occurrence of pathological fractures in elderly women [29] and diagnosing aseptic loosening of hip arthroplasty [30]. Concerning serum DPD, Southwood et al. [31] verified that the measurement of serum DPD levels can be effective for the assessment of the fracture healing process and early diagnosis of osteomyelitis. However, and in contrast with the present study, the authors verified higher serum levels of DPD in the non-union group at the 4th postoperative week than in the non-infected control group. These distinct results could be related with the different models designed to reproduce a non-union process, namely a CSD with periosteal cauterization or the inoculation of colony-forming units of Staphylococcus aureus in a fracture gap.

The high inter-individual variation observed in the control group for all the assessed parameters, even under standardized conditions, could decrease overall suitability if this variation is not taken into account. Similar to previous reports in other studies, the major limitation for the application of BTMs relates to their variability [32].

In conclusion, serum BALP, OC, TRAP, DPD and PIIINP levels could be useful as non-invasive auxiliary tools with other complementary methods for predicting the outcome of traumatic bone fractures. Impaired healing processes are associated with abnormally high amounts of collagen type-III expressed by osteoblasts on woven bone surfaces at an early post-operative time-point and are correlated with higher serum PIIINP levels observed in these patients. Consequently, such findings suggest that serum PIIINP levels can be a promising marker to detect fracture healing disturbances.

Cristina P. Sousa acknowledges the Portuguese Foundation for Science and Technology (FCT) for her PhD scholarship (Grant $\mathrm{N}^{\circ}$ SFRH/BD/45018/2008).

\section{Conflict of interest}

All authors have no conflicts of interest.

\section{References}

[1] Vasikaran S, Cooper C, Eastell R, Griesmacher A, Morris HA, Trenti T, et al. International Osteoporosis Foundation and International Federation of Clinical Chemistry and Laboratory Medicine position on bone marker standards in osteoporosis. Clin Chem Lab Med 2011;49:1271-4.

[2] Vasikaran S, Eastell R, Bruyere O, Foldes AJ, Garnero P, Griesmacher A, et al. Markers of bone turnover for the prediction of fracture risk and monitoring of osteoporosis treatment: a need for international reference standards. Osteoporosis Int 2011;22:391-420.

[3] Stoffel K, Engler H, Kuster M, Riesen W. Changes in biochemical markers after lower limb fractures. Clin Chem 2007:53:131-4.

[4] Veitch SW, Findlay SC, Hamer AJ, Blumsohn A, Eastell R, Ingle BM. Changes in bone mass and bone turnover following tibial shaft fracture. Osteoporosis Int 2006:17:364-72.

[5] Moghaddam A, Muller U, Roth HJ, Wentzensen A, Grutzner PA. Zimmermann G. TRACP $5 \mathrm{~b}$ and CTX as osteological markers of delayed fracture healing. Injury $2011 ; 42: 758-64$.

[6] Marchelli D, Piodi LP, Corradini C, Parravicini L, Verdoia C, Ulivieri FM. Increased serum OPG in atrophic non-union shaft fractures. J Orthopedic Traumatol 2009;10:55-8.

[7] Mukhopadhyay M, Sinha R, Pal M, Bhattacharyya S, Dan A, Roy MM. Role of common biochemical markers for the assessment of fracture union. Indian J Clin Biochem 2011;26:274-8.

[8] Cox G, Einhorn TA, Tzioupis C, Giannoudis PV. Bone-turnover markers in fracture healing. J Bone Joint Surg Am 2010;92B:329-34.

[9] Arens D, Sigrist I, Alini M, Schawalder P, Schneider E, Egermann M. Seasonal changes in bone metabolism in sheep. Vet J 2007;174:585-91.

[10] Newman E, Turner AS, Wark JD. Tthe potential of sheep for the study of osteopenia - current status and comparison with other animal-models. Bone 1995; 16:S277-84.

[11] Liesegang A, Sassi ML, Risteli J. Diurnal variation in concentrations of various markers of bone metabolism in growing female goats and sheep. Anim Sci 2003; 77:197-203.

[12] Gundberg CM, Markowitz ME, Mizruchi M, Rosen JF. Oosteocalcin in humanserum - a circadian-rhythm. J Clin Endocrinol Metab 1985;60:736-9.

[13] NRC. Nutrient Requirements of Sheep. 6th ed. Washington DC: National Academic Press; 1985.

[14] Turner AS, Alvis M, Myers W, Stevens ML, Lundy MW. Cchanges in bonemineral density and bone-specific alkaline-phosphatase in ovariectomized ewes. Bone 1995; 17:S395-402.

[15] Mende LM, Huq NL, Matthews HR, Chapman GE. Pprimary structure of osteocalcin from ovine bone - dabitc sequencing of 4-hydroxyproline and gamma-carboxyglutamate residues. Int J Pept Protein Res 1984;24:297-302.

[16] Seebeck P, Bail HJ, Exner C, Schell H, Michel R, Amthauer H, et al. Do serological tissue turnover markers represent callus formation during fracture healing. Bone 2005;37:669-77.

[17] Hak DJ, Fitzpatrick D, Bishop JA, Marsh JL, Tilp S, Schnettler R, et al. Delayed union and non-unions: epidemiology, clinical issues, and financial aspects. Injury 2014;45(Suppl. 2):S3-7.

[18] Coulibaly MO, Sietsema DL, Burgers TA, Mason J, Williams BO, Jones CB. Recent advances in the use of serological bone formation markers to monitor callus development and fracture healing. Crit Rev Eukaryot Gene Expression 2010;20:105-27.

[19] Murshed M, Harmey D, Millan JL, McKee MD, Karsenty G. Unique coexpression in osteoblasts of broadly expressed genes accounts for the spatial restriction of ECM mineralization to bone. Genes Dev 2005;19:1093-104.

[20] Lian JB, Stein GS. Concepts of osteoblast growth and differentiation - basis for modulation of bone cell-development and tissue formation. Crit Rev Oral Biol Med 1992;3:269-305.

[21] Cremers S, Garnero P, Seibel MJ. Chapter 87 - biochemical markers of bone metabolism. In: Bilezikian JP, Raisz LG, Martin TJ, editors. Principles of Bone Biology. San Diego, California: Academic Press; 2008. p. 1857-81. 
[22] Emami A, Larsson A, Petren-Mallmin M, Larsson S. Serum bone markers after intramedullary fixed tibial fractures. Clin Orthopedic Relat Res 1999;22:220-9.

[23] Herrmann M, Klitscher D, Georg T, Frank J, Marzi I, Herrmann W. Different kinetics of bone markers in normal and delayed fracture healing of long bones. Clin Chem 2002;48:2263-6.

[24] Oni OO, Mahabir JP, Iqbal SJ, Gregg PJ. Serum osteocalcin and total alkaline phosphatase levels as prognostic indicators in tibial shaft fractures. Injury 1989;20:37-8.

[25] Klein P, Bail HJ, Schell H, Michel R, Amthauer H, Bragulla H, et al. Are bone turnover markers capable of predicting callus consolidation during bone healing. Calcif Tissue Int 2004:75:40-9.

[26] Kurdy NM. Serology of abnormal fracture healing: the role of PIINP, PICP, and BsALP. J Orthopedic Trauma 2000;14:48-53.

[27] Lawton DM, Andrew JG, Marsh DR, Hoyland JA, Freemont AJ. Mature osteoblasts in human non-union fractures express collagen type III. Mol Pathol 1997;50:194-7.
[28] Halleen JM. Tartrate-resistant acid phosphatase 5B is a specific and sensitive marker of bone resorption. Anticancer Res 2003;23:1027-9.

[29] Gerdhem P, Ivaska KK, Alatalo SL, Halleen JM, Hellman J, Isaksson A, et al. Biochemical markers of bone metabolism and prediction of fracture in elderly women. J Bone Miner Res 2004;19:386-93.

[30] Landgraeber S, Loer F, Heep H, Classen T, Grabellus F, Totsch M, et al. Tartrateresistant acid phosphatase $5 \mathrm{~b}$ and $\mathrm{C}$-terminal telopeptides of type I collagen as markers for diagnosis of aseptic loosening after total hip replacement. Arch Orthopaedic Trauma Surg 2010;130:441-5.

[31] Southwood LL, Frisbie DD, Kawcak CE, Mcllwraith CW. Evaluation of serum biochemical markers of bone metabolism for early diagnosis of nonunion and infected nonunion fractures in rabbits. Am J Vet Res 2003;64:727-35.

[32] Seibel MJ. Biochemical markers of bone turnover: part I: biochemistry and variability. Clin Biochem Rev 2005;26:97-122. 